\title{
A IMPORTÂNCIA DA FRUTICULTURA PARA OS AGRICULTORES FAMILIARES DA REGIÃO DE JALES-SP ${ }^{1}$
}

\author{
RICARDO ALESSANDRO PETINARI ${ }^{2}$, MAURO JOSÉ ANDRADE TERESO ${ }^{3}$, \\ SÔNIA MARIA PESSOA PEREIRA BERGAMASCO ${ }^{3}$
}

RESUMO- Este trabalho teve como objetivo geral analisar a importância da fruticultura para os agricultores familiares do EDR (Escritório de Desenvolvimento Rural) de Jales, especificamente em três municípios, (Marinópolis, Santa Albertina e Santa Salete), tanto na manutenção das famílias no campo como na geração de postos de trabalho. Para a obtenção dos dados relativos à elaboração deste trabalho, foram aplicados questionários e realizadas entrevistas junto aos produtores das microbacias dos respectivos municípios, abordando questões sociais, econômicas e produtivas. A fruticultura destacou-se no EDR em termos de Valor Bruto da Produção, sendo que, dentre as frutas, a laranja e a uva apresentaram os melhores resultados. A fruticultura, principalmente a viticultura, mostrou-se capaz de gerar renda e manter os produtores no campo, bem como dar emprego aos filhos desses produtores, proporcionando, com isso, boas condições de sobrevivência às famílias, configurando-se como uma boa alternativa para as pequenas propriedades.

Termos para indexação: produção de frutas, agricultura familiar, geração de renda, permanência no campo.

\section{THE IMPORTANCE OF THE FRUIT GROWING FOR THE FAMILY FARMERS FROM THE REGION OF JALES-SP}

ABSTRACT- The objective of the present study is to analyze the importance of fruit growing for the family farmers from the EDR (Rural Development Office) of Jales, specifically in three cities, Marinopolis, Santa Albertina and Santa Salete, concerning the maintenance of the families in the field as well as the generation of jobs. In order to collect data to elaborate this study, questionnaires were applied and interviews were done together with the producers from the micro-basins of the respective cities, particularly on the social, financial and productive policies. The fruit growing highlighted in the EDR in terms of Gross Value of Production. Among the fruits, the orange and the grape have presented the best results. Mainly grape growing reveled capable of generating income and keeping the producers in the field, as well as providing jobs for the children of these producers, and offering good economical conditions for the families, showing to be a good alternative for the small farmers.

Index-terms: fruits production, family farm, generation of income, permanence in the field.

\section{INTRODUÇÃO}

A agricultura familiar no Brasil, com seu enorme potencial produtivo, contribui na geração de renda e postos de trabalho para as famílias que vivem no campo, o que a torna um importante mecanismo para o desenvolvimento rural (Guanzirolli et al., 2002).

No Estado de São Paulo, a agricultura familiar também se mostra importante. Um estudo desenvolvido por pesquisadores do Instituto de Economia Agrícola (IEA) da Secretaria de Agricultura de São Paulo, caracterizando as principais regiões do Estado em que esse tipo de agricultura mais se destaca, revelou que a região noroeste do Estado, especificamente o Escritório de Desenvolvimento Rural de Jales, é uma das mais representativas em termos de propriedades familiares, sendo esse EDR o único no Estado, em que a área ocupada por essas propriedades excede mais da metade do total.

Trata-se de uma região que tem sua economia essencialmente agrícola e, desde o início da colonização, a cafeicultura e a bovinocultura foram suas principais atividades.

Nas últimas décadas, além da bovinocultura, outra atividade também vem ganhando destaque nessa região. É a produção de frutas, que está concentrada, principalmente, em pequenas propriedades. Na maioria delas, predomina o trabalho familiar, havendo a contratação de trabalhadores temporários na época da colheita dos frutos. Dessa forma, a produção familiar contribui para o sustento da família e gera empregos, proporcionando boas condições de vida para seus membros.

Segundo Fayet (2001), a fruticultura tem uma perspectiva de mercado muito mais favorável do que os grãos, por exemplo, tanto no País como no mercado de exportação. Em virtude da diversidade climática e das novas tecnologias existentes no Brasil, é possível produzir praticamente o ano inteiro, o que não ocorre nas principais regiões fruticultoras do mundo. A fruticultura demanda mão-de-obra intensiva e qualificada, fixando o homem no campo e, na maioria dos casos, permite boas

${ }^{1}$ (Trabalho 135-07).Recebido em: 24-05-2007. Aceito para publicação em: 07-01-2008. Texto elaborado a partir da tese de doutorado do primeiro autor, defendida junto ao curso de Pós-Graduação em Planejamento e Desenvolvimento Rural Sustentável da FEAGRI/UNICAMP, sob a orientação do segundo e terceiro autores.

${ }^{2} \mathrm{Eng}^{\circ} \mathrm{Agr}^{\circ}$. MSc. Doutor pela FEAGRI/UNICAMP, “Bolsista do CNPq - Brasil”, e-mail: ricardopetinari@ig.com.br (Cidade Universitária Zeferino Vaz, s/n, Barão Geraldo, Campinas-SP, cep. 13083-970, caixa postal. 6011).

${ }^{3}$ Professores da FEAGRI/UNICAMP, e-mail: mauro@agr.unicamp.br; sonia@agr.unicamp.br (Cidade Universitária Zeferino Vaz, s/n, Barão Geraldo, Campinas-SP, cep. 13083-970, Caixa Postal. 6011). 
condições de vida para uma família que tenha pequena área agrícola.

Assim, este trabalho teve como objetivo geral analisar a importância da fruticultura para os agricultores familiares do EDR de Jales, especificamente em três municípios, (Marinópolis, Santa Albertina e Santa Salete), tanto na manutenção das famílias no campo como na geração de renda e postos de trabalho, uma vez que a pecuária também tem grande destaque na região.

\section{MATERIAL E MÉTODOS}

Foi definida como região de estudo o noroeste do Estado de São Paulo, por conta da importante presença da agricultura familiar e em especial o EDR de Jales, pela presença mais significativa desse segmento, quando comparado a outros EDRs paulistas. Estudos realizados por Carvalho \& Kuhn (1999), caracterizando a agricultura familiar no Estado de São Paulo, mostram que o EDR de Jales é o único do Estado em que a área ocupada pelas propriedades com menos de 50 ha excede $50 \%$ do total, chegando a $77 \%$ aproximadamente das propriedades.

O Escritório de Desenvolvimento Rural (EDR) de Jales (ou Regional de Jales), cuja sede dista $600 \mathrm{~km}$ da Capital paulista, abrange 22 municípios em uma área de 311.733,2 ha.

Para a delimitação do universo de pesquisa, tomou-se como base o Programa Estadual de Microbacias Hidrográficas do governo paulista, selecionando-se os municípios que mais se destacam, no EDR de Jales, em termos de subvenções em Projetos Comunitários (Projetos de Empreendimento Comunitário - PEC) e Projetos Individuais (Projetos Individuais da Propriedade - PIP), projetos esses delineados pelo Programa. Assim, o levantamento dos dados necessários à realização do trabalho foi efetuado junto a produtores rurais das microbacias dos municípios de Marinópolis, Santa Albertina e Santa Salete.

Os dados necessários para a elaboração deste trabalho foram obtidos com os técnicos do EDR de Jales, por meio de entrevistas e documentos fornecidos pelos mesmos. Quanto aos dados referentes às microbacias hidrográficas nos municípios estudados, estes foram obtidos junto à Coordenadoria de Assistência Técnica Integral (CATI) de Jales, além de informações fornecidas pelos agrônomos das Casas de Agricultura dos referidos municípios e que atuam diretamente nas referidas microbacias.

Já os dados sobre os agricultores familiares foram obtidos em 2005/2006, por meio da aplicação de questionários e entrevistas em que se buscou abordar questões sociais, econômicas e produtivas.

Foram pesquisados 20 produtores na microbacia de Marinópolis, 26 em Santa Albertina e 28 em Santa Salete, de acordo com critérios predefinidos, tais como: 1) ter a renda familiar relacionada à atividade agropecuária; 2) ser dono da propriedade ou pertencente à família, e 3) área explorada de até 50 ha.

As entrevistas foram aplicadas, principalmente, com o chefe da família (homem ou mulher), ocorrendo alguns casos em que houve a participação de outros membros da família (pai, esposa, filhos e outros).

\section{RESULTADOS E DISCUSSÃO}

\section{Caracterização fundiária do EDR de Jales}

No que diz respeito à estratificação fundiária da região, observou-se (Figura 1) que 59\% (4.968) do número total de UPAs - Unidades de Produção Agropecuária - (8.403) possui área inferior a 20 ha, ocupando apenas 15,5\% (48.316,30 ha) da área total da região de Jales (311.733,2 ha). Também se observou que $86 \%$ do total de propriedades possuem área inferior a 50 ha, ocupando $38 \%$ da área total. Por outro lado, $0,66 \%$ do número total de propriedades rurais com mais de 500 ha detém quase $20 \%$ da área total do EDR de Jales.

$\mathrm{Na}$ verdade, foi esta estrutura agrária, onde predominam unidades de produção com áreas inferiores a 20 ha, que levou ao desenvolvimento da olericultura e da fruticultura na região, permitindo que $88 \%$ do número total de UPAs tenham familiares do proprietário trabalhando na propriedade, que $24 \%$ tenham trabalhadores permanentes e que $38 \%$ do número total de UPAs contratem trabalhadores temporários (Francisco et al., 1997).

A diversificação agrícola revitalizou as pequenas propriedades rurais, permitindo bons resultados econômicos e a permanência de muitas famílias na zona rural, enquanto outras, mesmo tendo migrado para os centros urbanos, continuaram a trabalhar nas propriedades. Em 1980, 39\% da população da região de Jales residiam no setor rural, ao passo que, em 1996, esse número diminuiu para $20 \%$, sendo esse êxodo maior em municípios em que o processo de diversificação agrícola foi menos intenso (Pelinson, 2000).

Em termos de valor bruto da produção, das 10 principais atividades desenvolvidas em 14 municípios do EDR de Jales, conforme Tabela 1, pode-se verificar grande destaque para a pecuária de corte, seguida pela laranja, uva e leite.

$\mathrm{O}$ destaque das atividades ligadas à pecuária, no caso a bovinocultura de corte e a leiteira, pode ser explicado devido à predominância de áreas de pastagens no EDR de Jales, mesmo prevalecendo as pequenas propriedades, como foi apontado na estratificação fundiária (Figura 01).

Somando-se o valor bruto da produção das 10 principais atividades tem-se um total de $\mathrm{R} \$ 192.039 .860,50$ desse valor, relacionando-se as atividades ligadas à fruticultura - laranja, uva, limão e banana -que têm uma participação em torno de $44 \%$ do valor mencionado. Já a pecuária - corte e leite - representa $46 \%$. Esses dados de valor bruto da produção vêm mostrar os dois principais ramos de atividades desenvolvidas no EDR de Jales, ou seja, a pecuária e a fruticultura.

A cultura da uva apresentou dados interessantes, pois possui área (909 ha.) dez vezes menor quando comparada à da laranja (9.380 ha.). Contudo, seu valor bruto de produção é o terceiro dentre os principais do EDR, ficando atrás apenas da pecuária de corte e da laranja, que possuem áreas bem superiores.

\section{A diversificação da produção nos municípios pesquisados}

A maioria dos produtores que foram submetidos às entrevistas, possui propriedades com área total de até 50 ha. Os municípios de Marinópolis e Santa Salete apresentaram maior 
número de atividades por propriedade - quatro ao todo -, porém, quando se compara a média de atividades, em Marinópolis, houve 2,15 atividades por propriedade, com destaque para a cultura da laranja, presente em $70 \%$ das propriedades (Figura 2 ).

Já o município de Santa Albertina foi o que apresentou menor média de diversificação por propriedade, 1,31. Dentre as atividades desenvolvidas nas propriedades pesquisadas em Santa Albertina, a pecuária de leite foi a principal delas, presente em aproximadamente $70 \%$ das propriedades. Dos produtores que produzem leite, a maioria afirmou que estão nessa atividade por não terem alternativa, pois algumas culturas, como algodão e milho, devido aos baixos preços, são inviáveis economicamente, como menciona um produtor:

“(...) se você vai plantá algodão, milho, você tá sujeito a perdê a propriedade que você tem, (...) então você tem que tirá leite, é o menos ruim hoje. É bom? Não é bom. Compensa? Não é que ele compensa, é o menos ruim. Hoje o leite não é uma alternativa boa, mas é uma que você não fica endividado e se você começa, quisé fazê besteira, muita coisa, você não consegue pagá as divida, ai você tem que vendê as vaca, no fim caba com sua terra, não é fácil" (LA54).

Em Santa Salete, observaram-se resultados semelhantes aos de Marinópolis, em média foi 1,93 diversificação por propriedade, e a atividade que mais se destacou dentre as 28 propriedades pesquisadas foi a pecuária de leite, que estava presente em $57 \%$ das propriedades, seguida pela cultura da laranja $(43 \%)$, pecuária de corte $(29 \%)$ e a cultura da uva $(25 \%)$, conforme Figura 2.

Analisando as atividades dos três municípios, verificouse que Marinópolis e Santa Salete apresentaram maior diversificação por propriedade, em função da quantidade e distribuição percentual das atividades encontradas. Em Santa Albertina, não se observou tão grande diversificação, predominando a pecuária leiteira nas propriedades. Tal fato pode estar relacionado à presença de uma associação de produtores rurais de leite no município, em que os produtores entregam seu leite e recebem um preço melhor do que se fossem comercializálo sozinhos.

Notou-se que algumas propriedades, de modo geral, tinham, economicamente, apenas uma atividade como principal fonte de renda, o que é prejudicial. Em uma situação de queda dos preços, seus rendimentos também vão diminuir e, se essa situação é prolongada, muitos têm de abandonar a atividade, vender a propriedade e ir tentar a vida nas cidades.

A diversificação de atividades para a pequena propriedade familiar mostra-se de grande importância em termos de estratégia de reprodução social, pois garante rendimentos em períodos sazonais de produção, minimizando os riscos de se ter uma só atividade.

\section{Renda ligada às atividades agrícolas e pecuárias}

Dentre as rendas provenientes das atividades agrícolas e pecuárias, verificou-se que em função dos municípios, uma se destaca mais do que a outra. Em Marinópolis, a fruticultura, principalmente com a cultura da laranja, destacou-se como a principal geradora de renda para os produtores, seguida pela pecuária (corte e leite). Nesse município, a fruticultura foi responsável, em média, por $65,4 \%$ da renda agropecuária das propriedades, (Tabela 2), e a pecuária por $28,8 \%$, revelando, dessa forma, a importância que a fruticultura tem para esses produtores.

Diferentemente de Marinópolis, em Santa Albertina, as atividades de origem pecuária, corte e leite, foram as que mais contribuíram para a composição da renda agropecuária das propriedades, respondendo, em média, por aproximadamente $71 \%$ do valor total, já a fruticultura representou, apenas, $13,5 \%$ da renda total.

Em Santa Salete, houve uma mescla de rendas provenientes de atividades pecuárias e agrícolas. Verificando a Tabela 2, que traz a composição da renda agropecuária das propriedades pesquisadas, no município de Santa Salete, observa-se que, como em Marinópolis, a fruticultura, principalmente com a laranja, destaca-se como a principal geradora de renda para os produtores do município, seguida pela pecuária. Embora a renda da produção frutícola represente $53 \%$ do valor total, ela pode ser considerada alta em virtude de se ter uma gama maior de atividades agrícolas desenvolvidas no município, em comparação aos outros dois estudados, Marinópolis e Santa Albertina.

As rendas agropecuárias do município de Santa Salete vêm mostrar que há maior diversificação na exploração agrícola quando em comparação aos outros dois municípios, e isso se explica, em parte, pela estratificação fundiária do município, em que aproximadamente $92 \%$ das propriedades possuem área de até 50 ha, ou seja, composto basicamente por pequenas propriedades.

Nesse município, mesmo a atividade "pecuária leiteira" sobressaindo-se mais do que as outras, ela, porém, em termos de geração de renda, perde para as frutas. Assim, a pecuária leiteira constituía-se como uma renda secundária, pois existia sempre o cultivo de uma frutífera, que se destacava como a principal renda, como mencionado por um produtor:

"A minha renda vem só daqui do sítio mesmo, das uva e de outras coisa do sitio, das veis um saquinho de café, um pouquinho de laranja. Tinha pinha há uns dois anos atrás, deu uns troquinho, agora já mandei arrancá, deu gomose e não teve jeito mémo, virô um amarelão, passamo veneno, mas quê, foi pos quiabo mémo. Mas o que segura a renda mémo é a uva, com o dinheiro que nóis faz nela, tem que controlá para até vim a outra safra, sempre sobra né. Que nem esse ano se Deus ajudá que sobra um troquinho do café né, lá para o meio do ano, junho, julho. Depois tem um pouco de laranja, é pouco mas sempre vai dá uns troco, é pouco. E assim vai indo até vim a outra, outra veis" (AF53).

A safra da uva na região vai do final de julho até o final de dezembro, e a maior parte das pequenas propriedades tem nessa frutícola a principal fonte de renda. Desse modo, os produtores têm de passar o ano só com o dinheiro que fizeram durante a colheita da uva, esperando chegar a nova safra para, com isto, obter uma nova renda. Porém, ocorreram muitos casos de produtores que abandonaram seus parreirais, venderam a propriedade e foram para a cidade, pois até 2004 os preços recebidos por eles pela venda do $\mathrm{kg}$ da uva eram tão baixos que 
acabavam nem cobrindo os custos de produção. Porém, nos dias atuais, os preços recebidos melhoraram, e os viticultores estão contentes com a produção da uva.

\section{O papel da fruticultura nas propriedades familiares}

Um fato a ser destacado nos municípios estudados é o abandono do campo por parte dos jovens, filhos de produtores que vão em busca de oportunidades de trabalhos nas cidades. $\mathrm{O}$ motivo de esses filhos não estarem trabalhando com suas famílias, em parte, liga-se ao tamanho das propriedades, que são pequenas, à falta de mecanismos para aumentar a renda, pelo desfavorecimento da política agrícola e, também, devido ao fato de os jovens, talvez por suas próprias índoles ou até pelas "atratividades" das grandes cidades, buscarem novos horizontes e tentarem "construir sua vida" em outro local. A média em Marinópolis foi de 2,6 filhos por produtor, em Santa Albertina de 2,5 e no município de Santa Salete de 3,1.

Observa-se que, em Marinópolis, $65 \%$ dos filhos não trabalham na propriedade, ou por terem se casado e ido morar em outro local, ou por estudarem em outras cidades. Em Santa Albertina, o número de filhos que não trabalham na propriedade, é de quase $77 \%$.

No município de Santa Salete, foi onde se constatou o menor índice, em relação aos outros dois municípios, de filhos que não trabalham nas propriedades, sendo de aproximadamente $43 \%$. Nesse município, há mais filhos trabalhando junto com suas famílias.

Uma alternativa que pôde ser notada, mostrando-se viável, e que se configura como uma importante estratégia para que os filhos permaneçam trabalhando com suas famílias, foi a observada em Santa Salete. Nas propriedades em que a fruticultura é a principal atividade econômica, principalmente naquelas onde havia uva, verificou-se que a maior parte dos filhos(as) permanece para ajudar a família, conseguindo uma renda suficiente para sua independência financeira, não necessitando, com isso, buscar oportunidades de emprego nas cidades.

A renda gerada com a produção da uva permite manter os filhos e os próprios produtores trabalhando na propriedade, conseguindo assim boa renda para ambos.

"Aqui a renda mensal conforme fô vai saí uns 1.000 real mais ou menos, entre eu e meu filho. Qué dizê, uma base. Até agora o dinheiro da uva veio tudo embolado. Agora eu vô pegá, a hora que nóis apurá as coisa, pegá e dá um tanto para ele, comprá o que ele qué. Que nem essas novilha que matô, essas três é dele, então vai passá essas três para ele, para ele se virá né" (AF53).

Talvez a fruticultura, por ser uma atividade adequada e rentável para pequenas áreas, resulte em fatores benéficos para que os filhos, bem como seus pais, não necessitem abandonar o campo. Embora a laranja tenha-se mostrado como a principal atividade agrícola em Santa Salete, contudo proporcionando boa rentabilidade, ela não necessita de mão-de-obra intensa como a uva e também devido ao fato de precisar de uma área em torno de quatro vezes maior para obter o mesmo valor bruto de produção alcançado pela viticultura.

Assim, a uva, em pequenas áreas, consegue empregar um número maior de pessoas e proporcionar uma rentabilidade satisfatória aos produtores, muito embora, em anos anteriores, os preços recebidos pela venda do produto tenha sido desfavorável.

A região oeste do Estado de São Paulo, da qual a noroeste integra, vem-se destacando na produção de frutas, e, segundo o Programa Setorial Integrado de Promoção de Exportações de Sucos Tropicais, elaborado pela Associação das Indústrias Processadoras de Frutos Tropicais, essa região é apontada como um dos principais pólos de frutas tropicais no Brasil (Ruggiero, 2001).

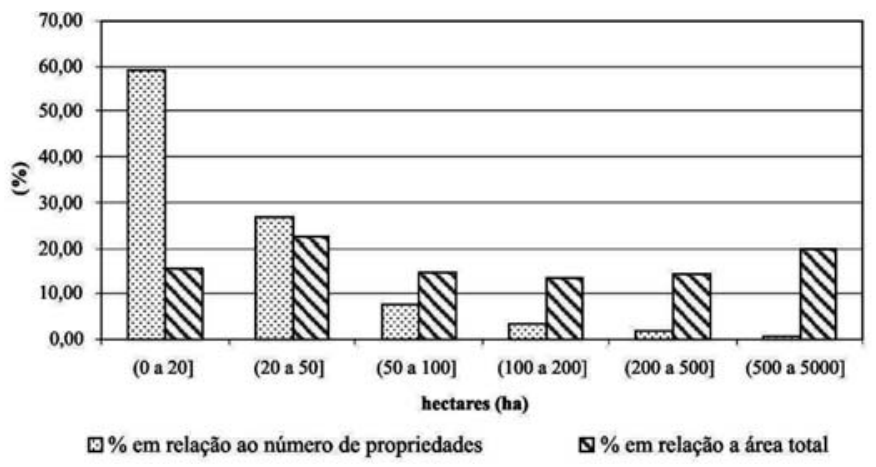

Fonte: LUPA/EDR/CATI de Jales, 1997.

FIGURA 1- Estratificação fundiária das propriedades do EDR de Jales-SP, 1997.

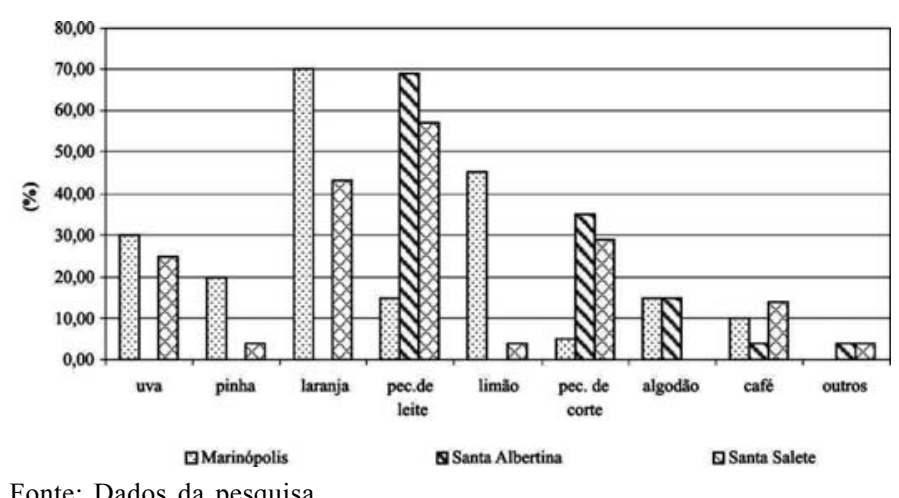

Fonte: Dados da pesquisa

FIGURA 2 - Principais atividades desenvolvidas nas propriedades pesquisadas dos municípios de Marinópolis, Santa Albertina e Santa Salete, maio de 2005 . 
TABELA 1 - Valor Bruto da Produção das principais atividades desenvolvidas nos 14 principais municípios do EDR de Jales no ano de 2005.

\begin{tabular}{lc}
\hline Produto & $\begin{array}{c}\text { Valor Bruto da Produção } \\
\text { (R\$) }\end{array}$ \\
\hline Bovinos para abate & $74.669 .315,00$ \\
Laranja & $50.247 .502,50$ \\
Uva comum para mesa & $15.981 .390,00$ \\
Leite tipo C & $14.150 .400,00$ \\
Limão & $13.944 .420,00$ \\
Algodão & $8.065 .683,00$ \\
Tomate & $7.156 .300,00$ \\
Área de capim para semente & $4.395 .600,00$ \\
Banana & $3.429 .250,00$ \\
Milho & $2.694 .880,00$ \\
\hline Fonte: EDR/CATI de Jales.
\end{tabular}

\section{CONCLUSÕES}

1-Pelo que se pôde constatar, a fruticultura mostrou-se como a principal alternativa para pequenas áreas, e as propriedades onde predomina essa atividade, desde que bem conduzidas, são capazes de manter toda a família trabalhando e conseguindo obter um bom retorno financeiro.

2-A boa participação das frutas no Valor Bruto da Produção do EDR de Jales vem mostrar o importante papel dessa atividade para os produtores rurais. Dentre as frutas cultivadas, sobressai-se a cultura da videira, que, em uma área bem menor em relação às outras atividades, se destaca como a terceira principal receita do EDR.

3-A situação financeira dos produtores familiares na região noroeste do Estado de São Paulo não é das melhores, porém, naquelas propriedades em que a base produtiva está voltada para a fruticultura, os produtores estão mais animados, conseguem boa produção e rentabilidade, quando em comparação àqueles que vivem da pecuária leiteira ou da exploração agrícola de culturas anuais.

4-Assim, a fruticultura, principalmente a uva, é capaz de gerar renda e manter os filhos, bem como os produtores, no campo, proporcionando boas condições de sobrevivência às famílias, mostrando-se como uma boa alternativa para as pequenas propriedades.

\section{REFERÊNCIAS}

CARVALHO, Y; KUHN, V. Agricultura familiar no estado de São Paulo: política e condições econômicas. Informações Econômicas, São Paulo, v.29, n.8, p.15-51, 1999.

FAYET, L.A. Virando o jogo com a fruticultura. Disponível em: $<$ http://www.parana-online.com.br>. Acesso em: 10 jul 2001.
TABELA 2 - Composição da renda agropecuária das propriedades pesquisadas nos municípios de Marinópolis, Santa Albertina e Santa Salete, maio de 2005.

\begin{tabular}{lccc}
\hline Produtos & Marinópolis & Santa Albertina & Santa Salete \\
\hline Frutas & $65,4 \%$ & $13,5 \%$ & $53,1 \%$ \\
Pecuária corte & $25,6 \%$ & $43,5 \%$ & $28,3 \%$ \\
Pecuária leiteira & $3,2 \%$ & $27,6 \%$ & $10,1 \%$ \\
Algodão & $1,2 \%$ & $13,0 \%$ & $0,6 \%$ \\
Outros produtos & $4,6 \%$ & $2,4 \%$ & $7,9 \%$ \\
Total & $\mathbf{1 0 0 , 0} \%$ & $\mathbf{1 0 0 , 0} \%$ & $\mathbf{1 0 0 , 0} \%$ \\
\hline
\end{tabular}

Fonte: Dados da pesquisa

FRANCISCO, V.L.F.S.; SUEYOSHI, M.L.S.; PINO, F.A.; CAMARGO, A.M.M.P. Censo Agropecuário no estado de São Paulo: resultados regionais. Informações Econômicas, São Paulo, v.27, n.11, p.75-77, 1997.

GUANZIROLI, C. E. et al. Novo retrato da agricultura familiar: o Brasil redescoberto. Brasília: Ministério do Desenvolvimento Agrário, 2000.74p.

PELINSON, G. J. B. Importância da viticultura na região noroeste do estado de São Paulo. In: BOLIANI, A.C.; CORRÊA, L.S. (Coords.). Culturas de uvas de mesa: do plantio à comercialização. Piracicaba: ALGRAF, 2000. p. 21-34.

RUGGIERO, C. (Ed.). Programa setorial integrado de promoção de exportações de sucos tropicais. Informativo Sociedade Brasileira de Fruticultura, Jaboticabal, v.20, n.2, p.4-5, 2001. 